\title{
Compreensões sobre ciência compartilhadas por alunos da básica antes e depois de intervenções pedagógicas
}

\author{
Understandings about science shared by students of the basic school before and aftes pedagogical \\ interventions
}

Wagner Rodrigues Silva

Universidade Federal do Tocantins - UFT - Tocantins - Brasil Jaquelene Mendes

Universidade Federal do Tocantins - UFT - Tocantins - Brasil

Márcia Helena Costa Ribeiro

Universidade Federal do Tocantins - UFT - Tocantins - Brasil

\begin{abstract}
$\longrightarrow$
Resumo: Compartilhamos os resultados de duas pesquisas interventivas realizadas em escolas brasileiras de ensino básico a partir da implementação de unidades didáticas como instrumentos orientadores dos processos de ensino e de aprendizagem. Esses instrumentos são compostos por atividades articuladas de práticas de linguagem e por diferentes gêneros textuais, além de serem informadas por abordagens pedagógicas de estudos sistêmicos-funcionais da linguagem e da educação científica, ambos desenvolvidos no campo indisciplinar da Linguística Aplicada. Com a comparação das respostas apresentadas pelos alunos participantes para um mesmo questionário, aplicado antes e após as intervenções pedagógicas, o resultado produtivo da implementação das unidades didáticas foi comprovado. Após as intervenções, os alunos complexificaram as próprias compreensões sobre ciência, o que foi revelado especialmente pela inclusão de pesquisas sobre fenômenos linguísticos nos contextos das práticas científicas descritos pelos alunos. Esse fato foi observado de forma mais expressiva nas respostas dos alunos da escola privada, os quais participaram da intervenção em que a própria língua materna foi objeto de investigação, diferentemente dos alunos da escola pública, que participaram da intervenção em que a Língua Portuguesa foi utilizada numa perspectiva instrumental. Nesse último caso, o português foi utilizado em função da investigação de objetos de pesquisa do interesse de outra disciplina escolar.
\end{abstract}

Palavras-chave: Educação científica; gêneros textuais; unidade didática.

\begin{abstract}
We share the results of two interventional researches carried out in Brazilian elementary schools based on the implementation of teaching units as instruments to guide the teaching and learning processes. These instruments are composed by articulated activities of language practices and different textual genres, in addition to being informed by pedagogical approaches from systemic-functional studies of language and scientific education, both developed in the antidisciplinary field of Applied Linguistics. With the comparison of the answers presented by the participating students to the same questionnaire, applied before and after the pedagogical interventions, the productive result of the implementation of the teaching units was confirmed. After the interventions, the students complexified their own understandings about science, which was revealed especially by including research on linguistic phenomena in the contexts of scientific practices described by students. This fact was observed more significantly in the responses of students from the private school, who participated in the intervention in which the mother tongue itself was the object of investigation, unlike the students in the public school, who participated in the intervention in which Portuguese was used in an instrumental perspective. In the latter case, Portuguese was used due to the investigation of research objects of interest to another school discipline.
\end{abstract}

Keywords: Scientific education; textual genre; teaching unit. 


\section{INTRODUÇÃO}

"Usar a inteligência para criar, experimentar, fazer e refazer coisas.

Não só experiências químicas, biológicas e ambientais, mas também na língua". (Estudante do $9^{\circ}$ ano do ensino fundamental, Pesquisa 1)

A epígrafe deste artigo refere-se a uma resposta dada por uma aluna do $9^{\circ}$ ano do ensino fundamental à pergunta: o que você compreende por fazer ciência? A resposta da aluna, extraída de um contexto privilegiado de ensino, numa perspectiva da educação científica (SILVA, 2021a; 2020a; 2019a; $2019 b$ ), remete ao processo de aprendizagem e ensino comprometido com a formação de cidadãos críticos e participativos. Cidadãos que usem a inteligência para, como afirmou a aluna, experimentar, criar, fazer e refazer empreendimentos que correspondam às demandas tão complexas de uma sociedade em constante transformação.

Em tempos de pandemia e num momento em que a ciência é tão essencial à difusão de informações pertinentes à preservação da saúde e do bem-estar das pessoas e, ao mesmo tempo, tão severamente confrontada por discursos contrapostos ao que é divulgado por cientistas das diversas áreas do conhecimento, incluindo aí o vasto espectro das humanidades (SILVA, 2020b), faz-se urgente e necessário um ensino que prepare os alunos para discernir fatos de versões, ciência de opinião. A partir de contextos situados em abordagens da educação científica, é possível extrair resultados bem sucedidos de alunos e alunas que puderam vivenciar e discernir criticamente acerca de procedimentos metodológicos de caráter científico e posicionaram-se mais reflexivamente em torno de demandas que requerem conhecimentos advindos da ciência (GARCIA; SILVA, 2020; GUIMARÃES; SILVA, 2020; MENDES; SILVA, 2020; MONTEIRO; SILVA, 2018; REIS; SILVA; FREITAS, 2021; SANTANA; SILVA; FREITAS, 2021).

Neste artigo, compartilhamos duas experiências pedagógicas produtivas que foram planejadas e implementadas a partir do trabalho cooperativo entre duas professoras do ensino básico e um docente do ensino superior. Essas experiências correspondem a pesquisas interventivas em duas escolas localizadas nas Regiões Norte e Nordeste do Brasil, sendo uma instituição pública e outra privada, respectivamente. As intervenções se caracterizaram pela implementação de unidades didáticas distintas caracterizadas pelo trabalho com diferentes práticas escolares de linguagem - oralidade, leitura, escrita, análise linguística -, mediadas por usos de gêneros textuais diversos. Tais práticas de linguagem foram organizadas nas unidades didáticas com o emprego do Circuito Curricular Mediado por Gênero - CCMG (CALLAGHAN; KNAPP; NOBLE, 2014[1993]; MARTIN, 2012[1999]; SILVA, 2015), utilizado como ferramenta pedagógica auxiliar.

Informadas pela abordagem pedagógica da educação científica, diversas unidades didáticas foram produzidas e utilizadas em investigações desenvolvidas no grupo de pesquisa Práticas de Linguagens - PLES (UFT/CNPq), especialmente por professoras e professores vinculadas ao Mestrado Profissional em Letras - ProfLetras (FIDELIS, 2018; GUIMARÃES, 2019; MENDES, 2018; REIS, 2016; RIBEIRO, 2018). Os resultados se mostraram bastante promissores, o que ilustramos neste artigo a partir da confrontação das percepções sobre ciência explicitadas por alunos das escolas mencionadas antes e após a implementação das unidades didáticas.

Este artigo está organizado em quatro seções principais, além desta Introdução, das Considerações finais e das Referências. Na primeira, apresentamos alguns recentes pressupostos teóricos que caracterizam a Educação Científica. $\mathrm{Na}$ segunda, sintetizamos as pesquisas realizadas por Mendes (2018) e Ribeiro (2018), no âmbito do ProfLetras, que deram a origem ao estudo apresentado neste texto. $\mathrm{Na}$ terceira, compartilhamos e problematizamos os resultados de dois pré-testes e dois pós-testes sobre concepções de ciência compartilhadas por alunos de um $9^{\circ}$ e $8^{\circ}$ anos do Ensino Fundamental, em uma escola privada e uma pública, antes e depois das intervenções pedagógicas focalizadas. Por fim, na quarta seção, compartilhamos mais precisamente 
algumas percepções construídas pelos discentes a respeito da prática científica em torno da língua(gem).

Faceta participativa da pesquisa em educação científica

Na literatura científica, publicada nas últimas décadas (HALLIDAY, 1996; HASAN, 1996; SILVA, 2021a; 2019a; SOARES, 2020; 2003; só para citar algumas), é possível observar construções teóricas sobre os processos distintos e complementares de alfabetização e letramento, desenvolvidas no campo dos estudos da língua(gem). Desse modo, sumariamente, o termo alfabetização corresponde à compreensão do funcionamento do sistema de escrita, resultando em habilidades de leitura e escrita, enquanto que o termo letramento é atribuído às habilidades de uso da escrita para as inúmeras e diversificadas práticas sociais (SILVA, 2021a; 2019a; SOARES, 2020; 2003).

Pesquisas recentes têm ampliado as concepções de alfabetização e letramento para a dimensão científica do conhecimento (MARTINS, 2010; CHASSOT, 2014; SOUSA, 2016; GUIMARÃES; SILVA, 2020; REIS; SILVA; FREITAS, 2021; SILVA, 2020a; SANTANA; SILVA; FREITAS, 2021; SILVA 2021a; 2020a, 2020b; 2019a; 2019b, 2019c; 2019d; só para citar alguns). Ao concentrar esses termos no campo do ensino de ciências, considera-se a expansão desses fenômenos para além de suas noções basilares. Assim, alfabetização científica corresponde à apropriação da linguagem das diferentes ciências, ou seja, diz respeito aos metaconhecimentos de aspectos propriamente científicos como critérios, procedimentos, métodos, termos técnicos, etc. O letramento científico, por sua vez, está associado ao uso cotidiano da linguagem e dos saberes sobre ciência, ou seja, a práticas sociais da leitura e escrita envolvendo aspectos constitutivos de domínios científicos.

Nessa perspectiva, o letramento científico pode se originar de práticas ou políticas de divulgação ou popularização da ciência, envolvendo as

\footnotetext{
${ }^{1}$ Os princípios pontuados por Silva (2020a) alinham-se a competências elencadas pelo autor (curiosidade, comunicação, colaboração, criatividade, criticismo, compaixão, controle e cidadania), inclusive com as
}

humanidades e, mais especificamente, por nosso interesse particular, as ciências da linguagem. Conforme Santos (2007), não basta saber ler o vocabulário, é preciso ser capaz de usar os conhecimentos científicos, não de maneira técnica, mas para interagir socialmente, inserindo-se em práticas sociais que demandam o exercício da cidadania de maneira crítica e consciente. Nas palavras de Silva (2020a), a distinção entre letramento e alfabetização científica "permite que pesquisadores e professores focalizem mais diretamente distintos aspectos constitutivos do processo de Educação Científica" (2020a, p. 11, itálicos do original). Ainda nos termos do referido autor, a abordagem de educação científica diferenciada deve partir de alguns princípios $^{1}$ necessariamente alinhados aos componentes curriculares tais como criatividade, curiosidade, relevância, persistência, colaboração, comunicação e investigação (SILVA, 2020a).

Situado na área de investigação da educação científica, o estudo apresentado neste artigo está inserido no campo não disciplinar da Linguística Aplicada (LA), caracterizado pela disponibilidade ao diálogo com pressupostos teóricos de origem diversa (SILVA, 2021b). Focalizamos aspectos humanistas, considerando algumas perspectivas sociais de usos da linguagem em contextos específicos, a fim de realçar o empoderamento dos participantes das intervenções pedagógicas focalizadas. Conforme defende Celani (1992, p. 22), a LA possui natureza essencialmente humanista e, "por estarem diretamente empenhados na solução de problemas humanos que derivam de vários usos da linguagem, os linguistas aplicados estão envolvidos em trabalho que tem uma dimensão essencialmente dinâmica" (itálico do original).

A partir de uma concepção transgressiva da LA, proposta por Pennycook (1998, p. 83), as pesquisas devem estar "sempre engajadas em práticas problematizadoras", que reconheçam os embates políticos e sociais na disputa pelo poder e dominação. Nesse sentido, a linguagem da ciência,

apresentadas na Base Nacional Comum Curricular BNCC (BRASIL, 2018). 
quando não compreendida pela comunidade em geral, pode contribuir para a manutenção de relações assimétricas entre os denominados especialistas e cidadãos comuns. Nas palavras de Halliday (1993, p. 84), "aprender ciências é a mesma coisa que aprender a linguagem da ciência. Os alunos têm que dominar essas dificuldades; mas, ao fazer isso, também estão dominando conceitos e princípios científicos".

Pesquisas dessa natureza visam melhorar a prática pedagógica dos educadores e satisfazer anseios pela aproximação entre saberes acadêmicos e escolares. Isso permite que os professores envolvidos repensem suas metodologias e reconheçam, nos saberes escolares, aqueles que são produtivos e os que não refletem boas práticas pedagógicas. É necessário produzir conhecimentos sustentáveis para o pleno funcionamento da escola. Esse aspecto é também caracterizador de pesquisas em LA, engajada com a promoção do autoquestionamento e da reflexão sobre a prática por parte de pesquisadores e professores (PENNYCOOK, 2001; 1998).

Em função da complexidade dos problemas humanitários atravessados pela linguagem, objetos centrais de estudos deste campo, à LA é atribuído o status de ciência "transdisciplinar ou, até mesmo, indisciplinar" (SILVA; GONÇALVES, 2014, p. 56). Como linguistas aplicados, transitamos entre diferentes campos do conhecimento a fim de buscar respostas aos problemas identificados envolvendo usos da linguagem. De acordo com Kleiman (2013, p. 43),

diálogos muito frutíferos vêm se desenvolvendo entre a Linguística Aplicada e outras ciências sociais e humanas [...] perseguindo respostas para investigações que se ocupam de questões em que a linguagem tem um papel constitutivo dos saberes nas configurações identitárias e nas relações que formam, conformam, deformam, informam, transformam as realidades que construímos.

A partir dessas noções humanitárias de pesquisa, é importante salientar a relevância e a necessidade de conhecimentos especializados para responsabilidade social. Os debates em torno da educação científica vão para além de concepções de cunho escolar, dizem respeito a questões tais como inclusão, identidade, ética, legitimidade, engajamento social e político. O exercício da cidadania demanda a observância dessas questões como direitos, tão cerceados em sociedades que convivem com a desigualdade. Interessa aos estudos do letramento minimizar ou eliminar algum tipo de exclusão social provocada pelo desconhecimento de usos legitimados da escrita em contextos específicos.

Nossos estudos compartilhados foram orientados por pressupostos teórico-metodológicos da pesquisa participante, caracterizada pelo trabalho colaborativo entre professoras-pesquisadoras e alunos (SILVA, 2010; SILVA; GONÇALVES, 2014). Configura-se como um "convite feito a várias vozes e segundo vários estilos, para que aprendamos também a não apenas pensar o outro através de nós mesmos - nossas práticas, nossas ideias, nossas posturas e teorias, mas a nós pensarmos a nós mesmos através do outro" (BRANDÃO; STRECK, 2006, p. 8). As professoras diretamente envolvidas nas intervenções pedagógicas vivenciaram a prática de pesquisa no local de trabalho. Instaurou-se um processo de mistura de experiências e saberes entre os participantes discentes e as professoras-pesquisadoras, desdobrando-se numa aprendizagem mútua e no compromisso social.

\section{Educação científica em contextos situados de pesquisas}

A investigação apresentada em Mendes (2018), retomada neste artigo como Pesquisa 1, foi realizada no Colégio Adventista de Imperatriz, localizado na cidade de Imperatriz, no Estado do Maranhão. Trata-se de um colégio privado pertencente ao Sistema Educacional Adventista, uma rede mundial de instituições com oferta da educação infantil ao ensino superior. A turma participante da pesquisa era formada por 34 alunos na faixa etária de 13 a 16 anos, os quais, no geral, demonstravam dificuldade para

\footnotetext{
2 Tradução para o português realizada livremente pelos autores deste artigo.
} 
produzir textos escritos observando mecanismos de textualidade. Na escola focalizada, a professorapesquisadora, licenciada em Letras, mantém vínculo empregatício há treze anos consecutivos, além de lecionar na rede pública e outras escolas particulares do município mencionado.

A Pesquisa 1 visou entender como a abordagem do letramento científico poderia contribuir para o desenvolvimento de práticas de linguagens oralidade, leitura, escrita e análise linguística -, contextualizadas no trabalho investigativo com o gênero propaganda. Para tanto, foi aplicada uma sequência de atividades pedagógicas reunidas em um instrumento orientador dos processos de ensino e de aprendizagem, denominado unidade didática, compreendida, de acordo com Silva (2015, p. 1044), como

\begin{abstract}
uma sequência de atividades didáticas organizadas a partir da articulação das diferentes práticas escolares de linguagens, em função do trabalho escolar com um número de gêneros selecionados como objetos de ensino, o que também pressupõe o uso do gênero como locus de contextualização para o estudo da língua(gem). A unidade didática funciona como um suporte onde o professor pode organizar as atividades de ensino em função da elaboração de um produto final coletivo, o qual pode ser um gênero textual produzido pelos alunos. Ou seja, as atividades didáticas configuradoras das práticas escolares de linguagens são desenvolvidas como etapas da produção do produto final.
\end{abstract}

A Figura 1 sintetiza as atividades realizadas durante a implementação da unidade didática da Pesquisa 1. $\mathrm{Na}$ sequência numérica, foram distribuídos os gêneros trabalhados durante a intervenção pedagógica em práticas de leitura e escrita desenvolvidas paralelamente. Os alunos compartilharam experiências e vivenciaram os gêneros em contextos de uso. Na primeira linha do organograma, localizam-se os gêneros (publicidade impressa, conto de fadas, artigo de divulgação de pesquisa de opinião, artigos de divulgação científica, capítulo de livro de divulgação científica) selecionados

\footnotetext{
3 Outros textos produzidos pelos alunos ao longo da implementação da unidade didática são denominados produtos intermediários (SILVA, 2015). Em outras
}

para o desenvolvimento das atividades de leitura acompanhadas pela prática de análise linguística. $\mathrm{Na}$ segunda linha, estão dispostos os gêneros produzidos pelos alunos (roteiro de entrevista, tabela, gráfico, artigo de divulgação científica, artigo de leitura dialogada). Correspondem às etapas de escrita e reescrita dos gêneros no cumprimento de suas funções sociais.

\section{Figura 1: Síntese das atividades na unidade didática da Pesquisa 1}

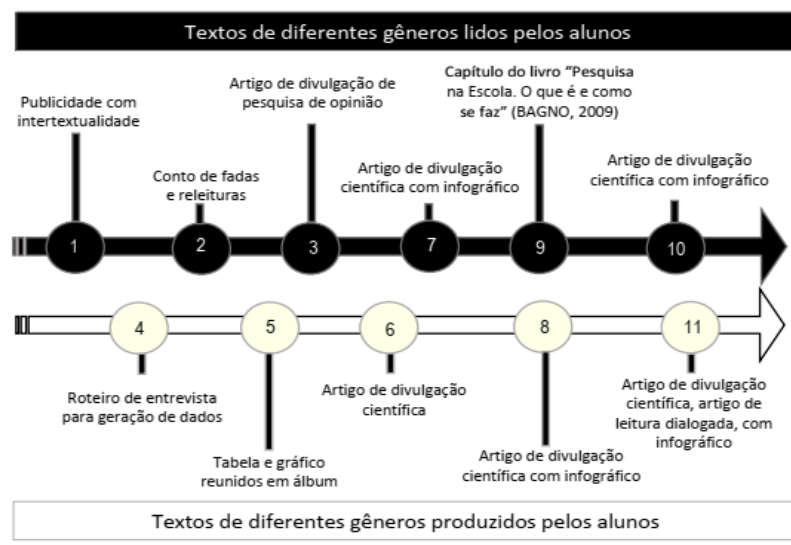

Fonte: Mendes e Silva (2020, p. 152)

O produto final da intervenção pedagógica foi a produção e publicação de artigos de divulgação científica e de leitura dialogada numa revista criada pelos discentes e pela professora. Esses textos foram caracterizados como gêneros âncoras, desencadeadores de todas as demais atividades realizadas a partir dos usos de outros textos elencados na Figura 1, denominados gêneros satélites, conforme denominações propostas por Silva $(2015)^{3}$. No Quadro 1, explicitamos resumidamente cada etapa da intervenção pedagógica conforme a sequência do organograma da Figura 1.

\section{Quadro 1 - Resumo das etapas da Figura 1}

1. Contato com diferentes publicidades impressas marcadas pelo fenômeno da intertextualidade, remetendo-se inclusive a contos de fadas conhecidos. Além da leitura, foram realizados registros escritos e análises orais sobre as propriedades do gênero satélite, incluindo aspectos textuais e contextuais;

2. Análise de contos de fadas para compará-los a diferentes versões e releituras das personagens

palavras, esses são os gêneros satélites produzidos na intervenção. 
literárias em diferentes suportes, considerando recursos verbais e imagéticos: livros infantis, animações, filmes e outras publicidades. Esse acervo investigado foi reunido em um álbum, caracterizado como banco de dados para análise em atividades subsequentes;

3. Leitura analítica de artigo de divulgação de pesquisa de opinião sobre temores de jovens universitários. A atividade modelou um roteiro de perguntas para os alunos utilizarem em função da verificação da compreensão leitora da comunidade escolar no tocante a publicidades impressas com intertextualidade;

4. Elaboração de roteiro de entrevista para diagnóstico da compreensão leitora da comunidade escolar (alunos, pais ou responsáveis e funcionários). O banco de dados do álbum fora utilizado na atividade;

5. Produção coletiva de tabelas e gráficos a partir de dados gerados com a aplicação do roteiro de entrevista. Esses produtos intermediários foram inseridos no álbum de dados de propriedade de cada grupo;

6. Produção de artigo de divulgação científica a partir do compartilhamento de experiências de pesquisa. Foram reunidas descobertas e resultados das entrevistas sobre a compreensão leitora de publicidades impressas por parte da comunidade;

7. Leitura analítica de artigo de divulgação científica com infográfico, com temáticas das ciências naturais conhecidas pelos alunos. Além do conhecimento do gênero, possibilitou a familiarização com procedimentos de investigação científica;

8. Retextualização de diferentes pesquisas sobre o efeito estufa em artigo de divulgação científica garantindo-se a prática de reescrita. Para tal propósito, os alunos receberam para análise uma compilação de textos sobre 0 assunto. As produções discentes foram lidas e discutidas em outras turmas;

9. Leitura analítica do texto "Basta uma sílaba", no livro "Pesquisa na escola: o que é e como se faz", de Bagno (2009, p. 82). Contribuiu para familiarizar os alunos com procedimentos investigativos sobre a língua portuguesa;

10. Leitura analítica do artigo de divulgação científica "Por que temos Sotaque?" (PEDROSA, 2015) acompanhado por infográfico. Demonstrou ser possível observar, explorar e analisar fenômenos linguísticos, falar e escrever sobre eles;

11. Produção de artigos de divulgação científica e artigos de leitura dialogada ${ }^{4}$. Esse último é uma variação do primeiro, resultante do percurso pedagógico trilhado ou, certamente, da escolarização sofrida pelo gênero modelado. Infográficos integraram a composição dos artigos, que foram publicados na Revista Língua Curiosa, criada a partir deste estudo. As pesquisas divulgadas resultaram da investigação sobre as publicidades impressas.

Fonte: Mendes e Silva (2020, p. 152).

4 O artigo de leitura dialogada é o resultado da retextualização de várias fontes de informações consultadas pelos alunos. Foi concebido de maneira heterogênea, caracterizada pelo cruzamento de
As produções escritas foram condicionadas às atividades modelares do mesmo gênero em práticas de leitura. Em outras palavras, evitou-se uma prática característica da tradição escolar: solicitação da produção textual de gêneros não trabalhados previamente e, por vezes, pouco conhecidos ou, até mesmo, desconhecidos dos alunos.

A investigação apresentada em Ribeiro (2018), retomada neste artigo como Pesquisa 2, foi realizada no Colégio Estadual Zico Dorneles localizado na área urbana do município de Juarina, no interior do estado do Tocantins. O município, originário de uma agrovila, possui pouco mais de dois mil habitantes. A maioria dos alunos vive no campo e começa cedo a desenvolver atividades agrícolas junto a suas famílias. A turma participante da pesquisa era formada por 27 alunos do $8^{\circ}$ ano, com idade entre 13 e 16 anos. Observamos, na maioria dos alunos da turma focalizada, grandes dificuldades em leitura, interpretação e, principalmente, produção escrita. Essa pesquisa foi implementada de maneira interdisciplinar, abrangendo os componentes de Língua Portuguesa e Geografia.

Licenciada em Letras, a professorapesquisadora atua há treze anos na escola onde desenvolveu a pesquisa. O professor participante da pesquisa é licenciado em Geografia e faz parte do corpo docente da instituição há doze anos. $\mathrm{Na}$ pesquisa, buscou-se compreender como a abordagem interdisciplinar do letramento científico, proposta para a reconstrução da história do espaço geográfico do município de Juarina, pôde contribuir para o fortalecimento do letramento crítico dos alunos. Também foi elaborada e implementada uma unidade didática interventiva

A Figura 2 sintetiza as atividades desenvolvidas durante a implementação da intervenção na Pesquisa 2. Mais uma vez, na sequência numérica, foram registrados os gêneros trabalhados durante a aplicação das atividades pedagógicas. Na primeira linha do organograma,

informações de fontes diferenciadas, conforme modelagem das atividades mediadoras no processo interventivo. 
encontram-se os gêneros selecionados para atividade de leitura (capítulo de livro de divulgação científica, projeto de pesquisa, relato histórico, mapa). $\mathrm{Na}$ segunda linha, estão representados os gêneros produzidos pelos alunos (projeto de pesquisa, roteiro de entrevista, mapa, relato histórico).

\section{Figura 2: Síntese das atividades na unidade didática da Pesquisa 2}

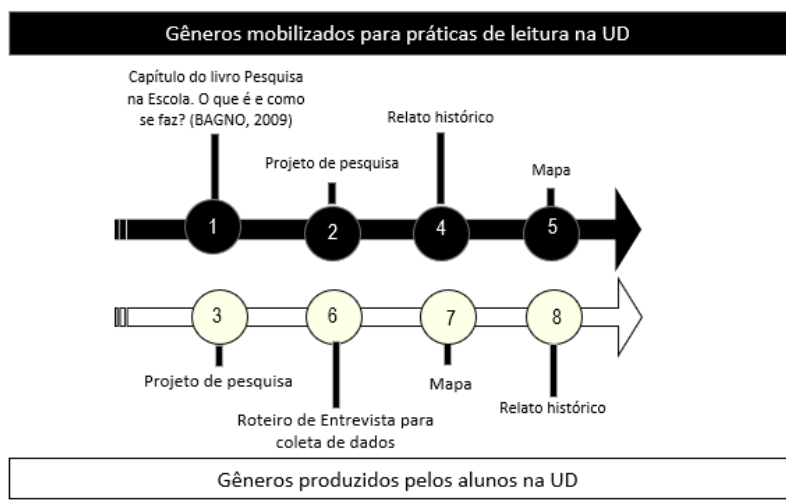

Fonte: autoria própria

O produto final da intervenção pedagógica foi a produção e publicação de relatos históricos em uma coletânea criada por discentes, professora de Língua Portuguesa e professor de Geografia. Esses textos foram caracterizados como gênero âncora, desencadeador de todas as demais atividades

realizadas a partir dos usos de outros textos elencados na Figura 2, denominados gêneros satélites, conforme proposto por Silva (2015). No Quadro 2, explicitamos resumidamente cada etapa da intervenção pedagógica conforme a sequência do organograma da Figura 2.

\section{Quadro 2 - Resumo das etapas da Figura 2}

1. Discussão sobre situações cotidianas em que realizamos pesquisas. Leitura do livro "Pesquisa na Escola: o que é e como se faz (BAGNO, 1988) e discussão interpretativa a partir da leitura de cada tópico do livro;

2. Leitura do projeto de pesquisa (BAGNO, 1988, p. 41-42) e análise quanto às funções sociais do gênero e estrutura de um projeto. Leitura de diferentes projetos de pesquisa e comparação quanto à caracterização, objetividade, linguagem, interlocutores;

3. Produção coletiva do produto intermediário projeto de pesquisa, a partir do qual se realizou o trabalho investigativo sobre a história do espaço geográfico do município;
4. Discussão sobre a importância do registro da história de um povo motivada pelo filme "Narradores de Javé". Leitura partilhada de relatos históricos, discussão sobre a função social do gênero, realização de atividades de interpretação e análise linguística;

5. Leitura de mapas (físico, político, econômico, demográfico) e análise quanto à função social do gênero e recursos gráficos e linguísticos utilizados nesses textos. Além disso, utilizando mapas do município, fez-se a definição coletiva das localidades a serem visitadas na pesquisa de campo;

6. Produção de roteiro de entrevista a ser realizada, pelos estudantes, nas pesquisas de campo;

7. Produção de mapas com rotas a serem percorridas em aula-campo;

8. Produção coletiva de relatos históricos como produtos finais, nos quais foram registrados os novos conhecimentos sobre o município onde os alunos viviam.

Fonte: Autoria própria

As atividades de produção textual das duas unidades didáticas seguiram o percurso metodológico do Circuito Curricular Mediado por Gênero - CCMG (ver anexo deste artigo), uma ferramenta pedagógica criada a partir da Linguística Sistêmico-Funcional (LSF) por Callaghan, Knapp e Noble (2014[1993]). Neste artigo, o que denominamos por CCMG é uma tradução e adaptação realizadas por Silva (2015) a partir do primeiro modelo dos ciclos de ensino/aprendizagem propostos no âmbito do Programa de Escolas Desfavorecidas em Sydney, Austrália (MARTIN, 2012[1999], p. 228).

O circuito consiste em uma ferramenta pedagógica que permite ao professor modelar 0 gênero a ser produzido, salientando aspectos característicos da materialidade textual e do contexto de produção e circulação. Essa ferramenta possibilita ao aluno alguma consciência do funcionamento dos gêneros como mediadores de atividades interativas em diferentes domínios sociais, desenvolvendo os letramentos de ação e reflexão por parte dos discentes (HASAN, 1996; SILVA, 2020c).

Nas duas investigações, a fim de verificar os resultados adquiridos com as intervenções, as professoras-pesquisadoras aplicaram um mesmo teste para cada pesquisa antes e depois da implementação das unidades didáticas, denominados, respectivamente, pré-teste e pós-teste. Os testes 
Compreensões sobre ciência compartilhadas

foram divididos em duas partes. Conforme Quadro 3, a primeira concentrava-se nas características e objetivos/habilidades específicos para cada pesquisa interventiva. Na Pesquisa 1, o teste destinava-se a investigar o nível de compreensão e análise crítica linguística de um texto publicitário que se utilizava dos efeitos de sentido promovidos pela intertextualidade. $\mathrm{Na}$ Pesquisa 2, o teste avaliava os conhecimentos acerca dos gêneros mapa e relato histórico, considerando os recursos gráficos e linguísticos característicos desses gêneros. 


\begin{tabular}{|c|c|c|}
\hline Turmas & $\begin{array}{l}9^{\circ} \text { ano do ensino fundamental } \\
34 \text { alunos }\end{array}$ & $\begin{array}{l}8^{\circ} \text { ano do ensino fundamental } \\
27 \text { alunos }\end{array}$ \\
\hline $\begin{array}{l}\text { Componente } \\
\text { curricular }\end{array}$ & Língua Portuguesa & Língua Portuguesa e Geografia \\
\hline $\begin{array}{l}\text { Pré/Pós } \\
\text {-testes } \\
1^{\text {a }} \text { parte }\end{array}$ & 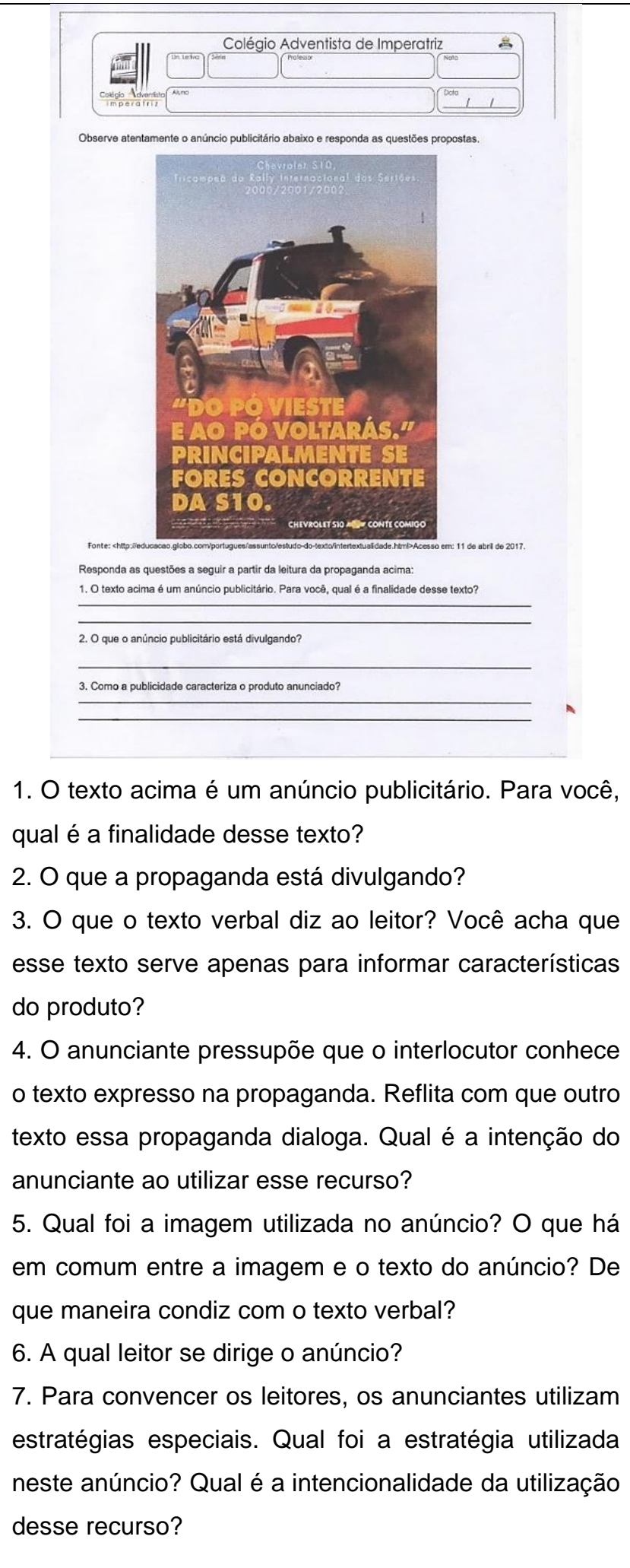 & 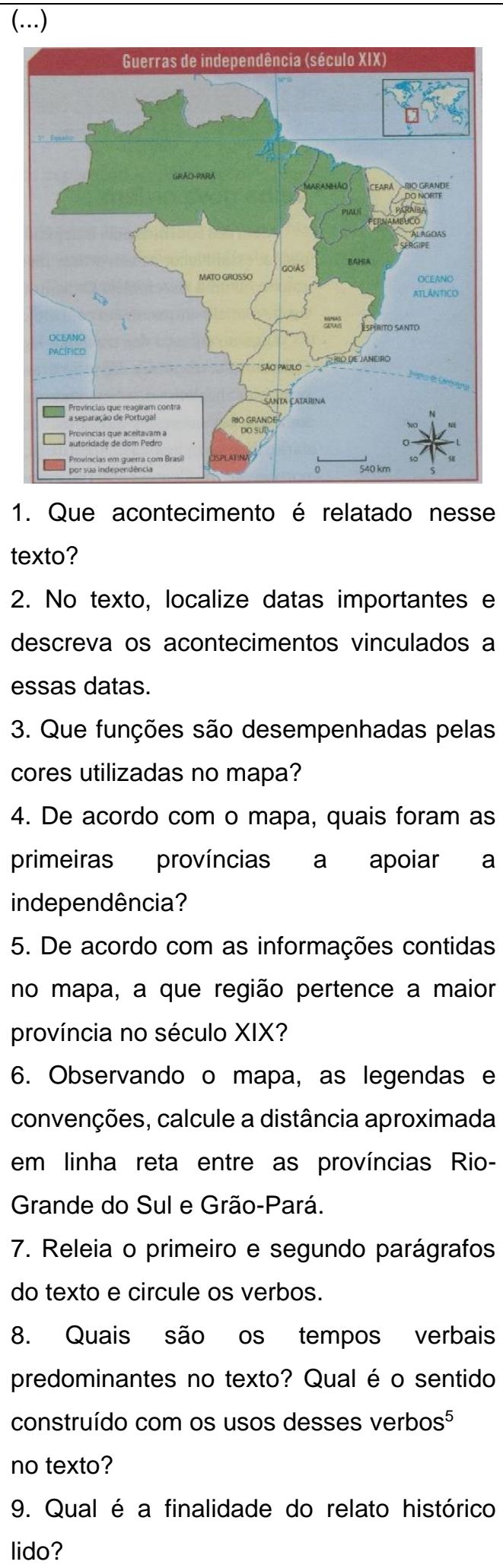 \\
\hline
\end{tabular}

Quadro 3: autoria própria.

\footnotetext{
${ }^{5}$ No teste, o Mapa da Guerra de Independência (século XIX) estava antecedido por um breve relato histórico.
} 
A segunda parte dos testes, composta por duas questões idênticas nas duas pesquisas focalizadas, investigava sobre as concepções ou compreensões que os alunos compartilhavam sobre ciência e situações que demandavam pesquisas científicas. Eis as questões propostas, que são focalizadas mais diretamente na seção seguinte deste artigo: (1) Certamente, você já ouviu falar sobre pesquisas científicas. O que você compreende por "fazer ciência"? (2) Cite algumas situações na sociedade em que os conhecimentos produzidos pelas ciências podem contribuir para solucionar ou aliviar demandas.

Enfatizamos, nas análises da próxima seção, os dados gerados que focalizaram a segunda parte dos testes aplicados nas duas pesquisas. Destacamos que era pretensão, ao comparar os resultados, analisarmos até que ponto as intervenções pedagógicas puderam subsidiar o aprimoramento ou desenvolvimento dos alunos em relação à percepção de demandas da ciência e suas implicações na sociedade, além de avaliar a aprendizagem e o desenvolvimento de habilidades relativas às diferentes práticas de linguagem.

\section{Concepções de ciência compartilhadas pelos alunos}

$\mathrm{Na}$ literatura especializada, é consenso a justificativa de que os objetivos e ações voltadas à promoção da educação científica se alinham à necessidade de preparação de cidadãos para a lida com as demandas da sociedade que, como afirma Martins (2010, p. 365), "de forma crescente, pauta-se pela presença da ciência e da tecnologia em situações cotidianas e com a preparação para o trabalho, tomada de decisão informada e exercício responsável da cidadania". As pesquisas aqui apresentadas demonstraram, nesse sentido, encaminhamentos propícios para a conscientização das características da natureza da ciência e dos processos de sua construção.

Nesse aspecto, a segunda parte do teste, que focalizava o entendimento compartilhado pelos alunos sobre conhecimentos científicos, demonstrou significativo avanço na visão de ciência e no reconhecimento de suas contribuições para a sociedade em diferentes áreas. Nos Gráficos 1 e 2, justapostos na sequência, referentes à Pesquisa 1, é possível visualizar o avanço mencionado na comparação entre o pré-teste e o pós-teste.

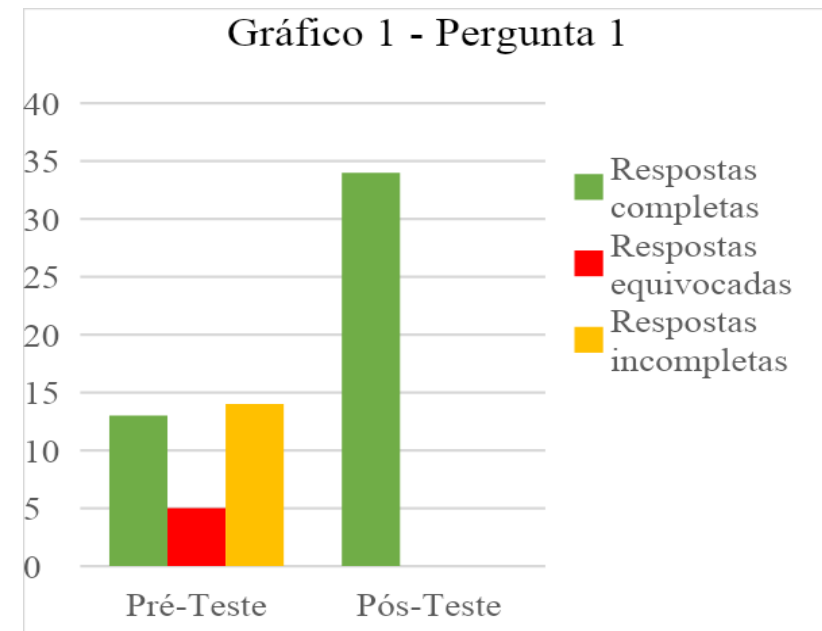

Gráfico 2 - Pergunta 2

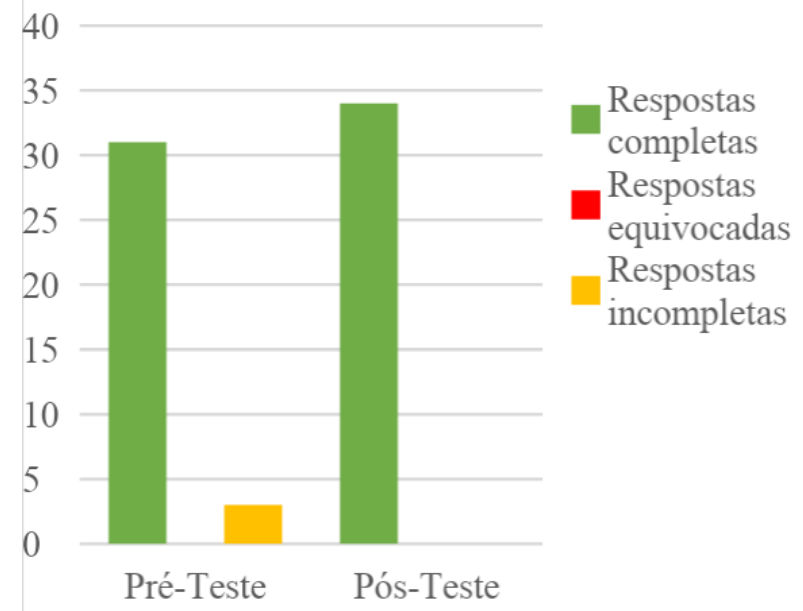

No decorrer da unidade didática, muitas questões sobre o valor da ciência e sua importância para a sociedade foram levantadas. Os alunos investigaram sobre a construção de um conhecimento científico, os procedimentos adotados, problematização de questões a serem investigadas e a importância de critério e seriedade na realização de uma pesquisa. Assim, ao desenvolverem as próprias investigações em torno das análises das propagandas, puderam vivenciar experiências inéditas de investigação linguística e descobriram que a ciência se 
desenvolve em uma diversidade de áreas do conhecimento.

No Gráfico 2, os resultados apresentados para a primeira pergunta do pré/pós-testes demonstraram que os alunos desprovidos de noções básicas a respeito do fazer científico passaram a se posicionar mais criteriosamente sobre o assunto e responderam com mais propriedade a respeito. Em resposta a essa mesma pergunta no pós-teste, todos os alunos demonstraram saber como a ciência é desenvolvida.

Conforme representado no Exemplo 1, retomando a epígrafe deste artigo, em resposta à segunda pergunta, que demandava a citação de situações em que os conhecimentos científicos contribuíam para solucionar e aliviar demandas sociais, os participantes evidenciaram situações diversas de atuação científica.

P1: Certamente, você já ouviu falar sobre pesquisas científicas. O que você compreende por "fazer ciência"?

A1. "Usar a inteligência para criar, experimentar, fazer e refazer coisas. Não só experiências químicas, biológicas e ambientais, mas também na língua".

P2: Cite algumas situações na sociedade em que os conhecimentos produzidos pelas ciências podem contribuir para solucionar ou aliviar demandas.

A1. "Na medicina em tratamento de várias doenças que não tinha cura; no meio alimentício; em estudos feitos na língua para o melhor conhecimento da mesma; conhecimento do próprio corpo; na tecnologia com novas formas de tornar tudo mais fácil, como na comunicação entre as pessoas e etc; na natureza, no funcionamento dos oceanos, no jeito de cada animal, nas belezas naturais e etc".

Exemplo 1: pós-teste - pesquisa 1

Pelas respostas, constatamos que a aluna conseguiu perceber a abrangência dos domínios de conhecimentos científicos para diferentes demandas sociais e reconheceu, dentre essas demandas, que a língua também pode ser objeto de investigação científica. O avanço desencadeado pelas novas abordagens adotadas no processo investigativo pode ser evidenciado na comparação entre as respostas do exemplo mencionado e a reprodução das respostas

6 Neste primeiro exemplo, reproduzimos as duas perguntas da segunda parte dos pré/pós-testes. Nos exemplos seguintes, as perguntas serão sinalizadas pelas dadas pela mesma aluna no pré-teste, conforme Exemplo 2.

P1. (A1) "Criar teorias e experimentos para solucionar ou responder algum 'porém'".

P2. (A1) "Derretimento das geleiras, limpezas de rios e mares, poluição, aproveitamento da água". Exemplo 2: pré-teste - pesquisa $1^{6}$

Ao comparar as respostas, podemos constatar que, no pós-teste, a aluna demonstrou maior domínio não apenas das concepções de ciência, mas no desenvolvimento, articulação e explanação das ideias, ou seja, nos elementos que compõem a textualidade na construção da sua resposta.

Em relação aos dados gerados na Pesquisa 2, representamos, nos Gráficos 3 e 4, os resultados produzidos a partir das respostas para a segunda parte do pré/pós-testes.

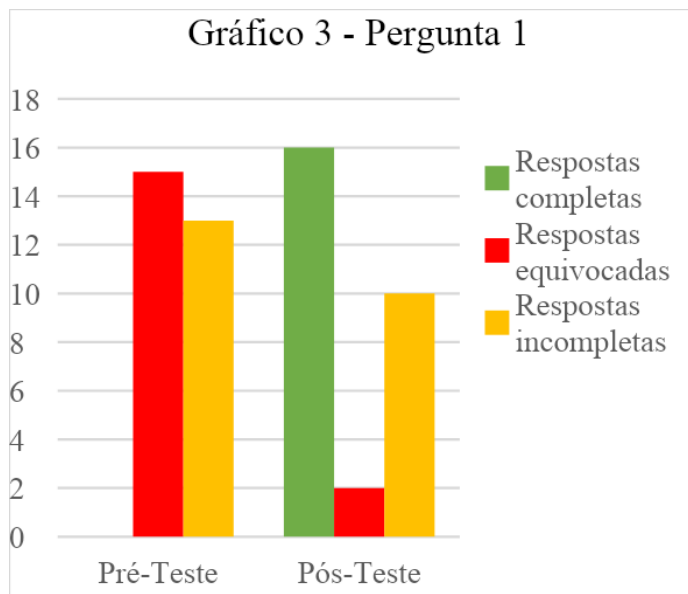

Gráfico 4 - Pergunta 2

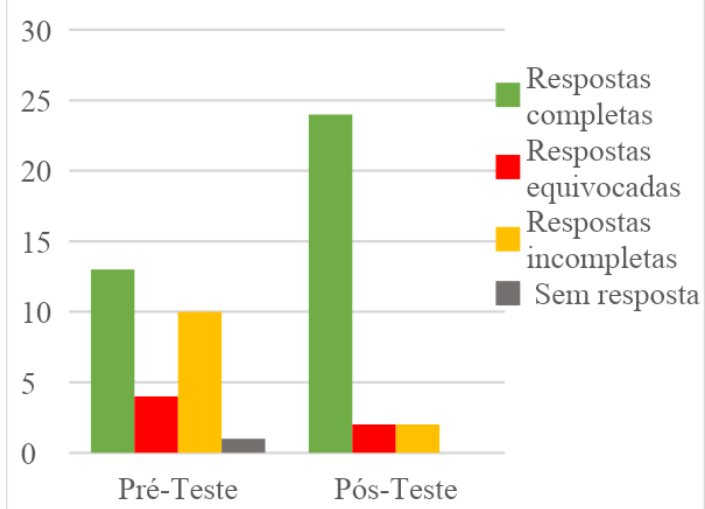

Fonte: Ribeiro (2018, p. 103; 106).

siglas P1 e P2, utilizadas para a primeira e segunda respostas, respectivamente. 
No âmbito da Pesquisa 2, a unidade didática não focalizou investigações sobre aspectos da língua portuguesa, mas a estruturação e execução de uma pesquisa para reconstrução da história do espaço geográfico do município. Nesse contexto, foram acionados conhecimentos científicos da disciplina de Geografia, bem como aspectos linguísticos dos gêneros textuais mobilizados para a realização do projeto interdisciplinar. Ao percorrer o CCMG com o gênero projeto de pesquisa e empreender a proposta investigativa do projeto elaborado, os estudantes experimentaram procedimentos da investigação científica.

Como se observa no Gráfico 3, em relação à Questão 1, nenhum aluno apresentou respostas completas. Nas respostas incompletas, os alunos associam a prática científica a descobertas da área das ciências naturais e tecnologias, com respostas como: "fazer coisas novas e aprender sobre as coisas"; "Descobrir novos seres e fazer experiências"; "Descobrir muitas coisas que quase ninguém conhece, fazer o povo ir à lua, inventar celulares novos, descobrir planetas, etc." Ainda que relacionassem o fazer científico a "descobertas" e desenvolvimento tecnológico, eles demonstraram pouco conhecimento sobre os procedimentos de pesquisa.

No pós-teste, como demonstrado no Exemplo 3 , em relação à mesma Questão 1, houve considerável aumento das respostas completas, nas quais, ainda que com alguma imprecisão, os alunos fizeram referência a procedimentos de pesquisas metodologicamente organizados.

\begin{tabular}{l}
\hline P1. (A2) "É buscar informações de maneira \\
organizada, fazer projetos que ajudam no \\
planejamento de nossas atitudes como pesquisas, \\
comparações, estudos e divulgação". \\
P1. (A3) "Para fazer ciência você precisa ser \\
organizado, fazer projeto com metodologia depois que \\
você pesquisa em jornais, revistas e internet e quando \\
tiver suas respostas ajunta tudo e faz o produto final". \\
Exemplo 3: pós-teste - pesquisa 2
\end{tabular}

As respostas do Exemplo 3 explicitam um diálogo consistente com a intervenção realizada.
Portanto, consideramos que a aplicação da proposta interventiva proporcionou aos participantes concepções mais sólidas sobre o fazer científico. $\mathrm{Na}$ seção seguinte, focalizamos algumas percepções dos discentes da Pesquisa 2 sobre a língua como objeto de investigação científica.

Em relação à Questão $2^{7}$, no pré-teste, conforme o Gráfico 4, treze alunos apresentaram respostas coerentes e completas. Essas respostas remetem, principalmente, às contribuições científicas evidentes no contexto sociocultural dos alunos.

P2. (A4) "Na região agrária, as máquinas, as plantas de laboratório, venenos poderosos".

P2. (A5) "remédios, automóveis, armas, aparelhos eletrônicos".

P2. (A6) "Purificadores de água, ajuda a limpar a água, remédio para ajudar a curar doenças, armas para combate, carro para locomoção".

$$
\text { Exemplo 4: pré-teste - pesquisa } 2
$$

Desse modo, ainda que tenham respondido coerentemente à solicitação, conforme representado no Exemplo 4, nenhum estudante fez menção a contribuições das descobertas científicas para as áreas das humanidades ou dos estudos da linguagem. A essa mesma pergunta, no pós-teste, vinte e quatro alunos, dentre os vinte e sete, responderam coerentemente apontando diferentes situações que demandam conhecimentos científicos de maneira mais ampla incluindo as humanidades e estudos linguísticos.

Esses resultados demonstraram os reflexos da implementação das propostas pedagógicas executadas, pois evidenciamos que, a partir da intervenção pedagógica orientada pela abordagem da educação científica, os alunos passaram a compreender a investigação científica para além das ciências naturais. Esses dados reafirmam a necessidade de se assumir na escola o paradigma emergente que confere "às ciências sociais antipositivistas uma nova centralidade" (SANTOS, 2008, p. 9).

\footnotetext{
${ }^{7}$ Relembramos aqui a Questão 2: cite algumas situações na sociedade em que os conhecimentos produzidos pelas
}

ciências podem contribuir para solucionar ou aliviar demandas. 
A fertilidade e as implicações dos conceitos de alfabetização e letramento científicos para o campo de educação em ciência se evidenciam bastante pertinentes para os propósitos de amenizar desigualdades e alcançar uma sociedade mais democrática. Conforme Silva (2020a, p. 19), "com culturas, crenças e saberes desprestigiados, o cidadão comum fica sujeito à exclusão, fracassa em interações características de contextos escolares e não escolares, inclusive nos próprios componentes curriculares, tradicionalmente conhecidos como disciplinas escolares". A partir da conscientização crítica das complexas relações entre ciência e sociedade, os sujeitos podem atuar de maneira mais engajada política e socialmente e contribuir para atenuar essas exclusões e fracassos elencados por Silva (2021a; 2020a).

Esta análise nos permite afirmar que a pouca familiaridade dos alunos participantes com práticas de pesquisas científicas na área de ciências naturais e, principalmente, na área das humanidades, incluindo aí os estudos da linguagem, foi minimizada a partir da implementação das atividades planejadas. Isso mostra a pesquisa interventiva como um caminho viável para promover a educação científica de alunos da escola básica.

\section{Concepções científicas sobre estudos de língua(gem) compartilhadas pelos alunos}

Nesta seção, apresentamos como as propostas pedagógicas nas aulas situadas nos contextos das Pesquisas 1 e 2 contribuíram para percepção da língua(gem) como objeto de investigação científica no componente de Língua Portuguesa. Lembramos que "quaisquer componentes curriculares compartilham demandas para inovação pedagógica e podem encontrar subsídios na abordagem da Educação Científica, afinal, estão atrelados a algum campo de conhecimento" (SILVA, 2020a, p. 13).

$\mathrm{Na}$ Pesquisa 2, dentre as vinte e quatro respostas completas para a pergunta acerca das contribuições da ciência para aliviar demandas da sociedade, houve um número expressivo de respostas - dezoito alunos, conforme ilustrado no Exemplo 5 que fizeram referência direta ou indiretamente a conhecimentos da área da linguagem, relacionando o avanço da ciência à compreensão de fenômenos da linguagem.

P2. (A7) "Através da ciência temos meios para conhecer as ramificações de nossa língua e descobrir a fundo a nossa língua, podemos conhecer o nosso corpo, o lugar onde vivemos, conhecer a natureza, a tecnologia, novos meios de pesquisa e contribuições para o planeta".

P2. (A8) "Carros não poluentes, papel reciclado, aprendemos mais a nossa e outras línguas, sabemos da vida de cantores, escritores, atores, e ainda descobrir e aprender palavras novas".

P2. (A9) "Remédios, satélites, estudos do universo, conhecimento sobre a linguagem, vida dos autores e diferentes idiomas".

$$
\text { Exemplo 5: pós-teste - pesquisa } 2
$$

Esses dados revelam um aspecto bastante pertinente em relação a estudos focalizados em investigações da própria língua. Os alunos da Pesquisa 2, apesar de apontarem uma visão mais ampla e consciente para a abrangência da ciência, incluindo os estudos da linguagem, quando mencionaram a área, fizeram-no de maneira mais imprecisa e restrita em relação a investigações propriamente linguísticas. É importante lembrar que a pergunta não focalizava essa área de conhecimento, de maneira que os alunos não foram precisamente induzidos para este encaminhamento. Provavelmente, as respostas dadas se devam ao fato de estarem inseridos mais especificamente no contexto de pesquisa comprometida com a (re)construção da própria história e do espaço geográfico por eles ocupado. Isso evidencia a necessidade da não restrição da disciplina Língua Portuguesa como auxiliar no trabalho investigativo sobre outros campos do conhecimento, numa função instrumental.

Conforme Gráfico 2 da Pesquisa 1, dos trinta e quatro alunos que apresentaram respostas corretas para a pergunta acerca das contribuições da ciência para aliviar demandas sociais, vinte e cinco mencionaram investigações voltadas ao estudo da língua como exemplos de situações em que a ciência colabora para minimizar problemas de linguagem. Dentre essas respostas, além da citada no Exemplo 1, 
outras respostas, inseridas no Exemplo 6, demonstram a compreensão da língua como objeto de estudo científico de maneira mais pontual.

P2. (A10) "Estudos linguísticos podem resolver problemas da língua fazendo com que haja maior compreensão linguística dos alunos e geração de novos conhecimentos".

P2. (A11) "O estudo da língua portuguesa pode ser considerado uma ciência, pois há problemas que devem ser resolvidos assim como em outras áreas como medicina para combater doenças, arqueologia que busca entender os fósseis etc".

P2. (A12) "Podemos resolver questões dos efeitos linguísticos que a língua produz em diversas situações e cruzar textos diferentes que caminham para um mesmo sentido ou não".

P2. (A13) "É possível investigar os problemas de leitura e também da nossa escrita na escola quando entendemos por que eles ocorrem e como melhorar". P2. (A14) "Para saber usar a nossa língua para escrever e entender os textos de propagandas e outros".

P2. (A15) "Estudando a língua a gente pode entender como os textos diferentes usam modos diferentes e palavras diferentes de serem escritos, alguns vendem, outros contam, outros fazem crítica..."

Exemplo 6: pós-teste - pesquisa 1

É relevante mencionar que, na primeira aplicação do teste ${ }^{8}$, nenhum aluno havia apontado como resposta ${ }^{9}$ exemplos de situações científicas que se relacionassem à língua. Certamente, o fato de terem vivenciado suas próprias experiências de investigação linguística contribuiu para que os alunos visualizassem mais criteriosamente o fazer, a abrangência e a atuação da ciência nessa área específica.

Em contextos específicos que se alinhem a estudos da língua propriamente ditos, não é suficiente apresentar conhecimentos científicos aos alunos. É necessário criar oportunidades para que eles, de fato, submerjam em situações de aprendizagem para vivenciar momentos de investigação que lhes permitam desenvolver posturas mais questionadoras diante de fenômenos linguísticos, observar com criticidade e ampliar saberes a partir da curiosidade.

\footnotetext{
8 Os testes foram aplicados sem a interferência das professoras-pesquisadoras para resolução das questões, evitando-se a exposição dos alunos a situações constrangedoras.

${ }^{9}$ As categorias de respostas incompletas e equivocadas, geradas no pós-teste das duas pesquisas, não se
}

Ao longo da intervenção, os alunos inseridos na Pesquisa 1 entraram em contato com diferentes leituras e produções de textos que exploravam aspectos da própria língua. Ao final, construíram seus próprios artigos nos quais apresentavam as conclusões e descobertas alcançadas ao longo do processo de investigação. Como aponta Silva (2020a, p. 24), para legitimar conhecimentos desenvolvidos em aulas de língua materna, "os alunos precisam ser sensibilizados para elaborar perguntas sobre a língua(gem) em contextos situados". Esses aspectos podem ser apontados, mais precisamente, em algumas marcas da prática científica no contexto da Pesquisa 1:

as atividades de leitura e escrita foram executadas a partir da investigação científica sobre o funcionamento da linguagem;

o processo configurou-se no cruzamento de informações a partir de diferentes fontes de leitura para interpretações críticas e consistentes de textos publicitários;

os textos produzidos foram frutos de uma percepção consciente do recurso da intertextualidade para leitura, releitura e recontextualização de dizeres na geração de efeitos inesperados em textos publicitários; e as produções se constituíram por uma complexa atividade na ativação de processos cognitivos, linguísticos, textuais e de compreensão a partir de outros textos e conhecimentos prévios.

Esses processos de aprendizagem, a partir de vivências científicas em sala de aula, de certo modo dessacralizam a ciência ao aproximá-la do público comum. Assim, os alunos e a comunidade escolar podem compreender conhecimentos científicos não como algo isolado ou de alta complexidade. Passam a compreender que a ciência é feita a partir da curiosidade, observação, questionamento sobre como as coisas funcionam, busca por respostas, vivências e

restringem a alguns poucos alunos. Em outras palavras, alunos que responderam corretamente algumas questões do teste também responderam de maneira incompleta ou equivocada outras. 
aprendizado. Isso significa que as práticas científicas podem e devem ser democratizadas.

Por fim, realçamos que o planejamento em aulas de língua materna, sob a abordagem pedagógica da educação científica, pode sofrer mudanças substanciais, pois os objetos de conhecimento ("conteúdos" dos componentes curriculares) alinhamse a diversas competências a serem desenvolvidas junto aos alunos (SILVA, 2020a). Em outras palavras, tais objetos de conhecimento não precisam ser ignorados ou substituídos, podem ser ressignificados numa abordagem mais produtiva ou sustentável do estudo da língua materna.

\section{Considerações finais}

Pensar uma educação científica é pensar em uma educação que dê oportunidades para as crianças e jovens explorarem e entenderem o que existe ao seu redor nas diversas dimensões: humana, social, cultural e linguística. Isso pressupõe uma escola que desperte um olhar para a curiosidade, a criticidade, a problematização, a investigação, o que, por sua vez, envolve uma educação pautada no diálogo e na construção participativa de saberes, a exemplo da parceria entre pesquisador universitário e professoras da escola básica na produção das investigações aqui relatadas e, inclusive, na produção deste artigo.

O processo de ensino implica em um compromisso do professor com a consciência crítica do aluno, ao auxiliá-lo no desenvolvimento de habilidades que o capacitem a compreender a complexidade do mundo a sua volta, a fazer perguntas, a pensar em hipóteses que solucionem problemas, a analisar situações e a propor soluções. Segundo Silva (2020a, p. 21), "as escolas precisam proporcionar a formação de pessoas capazes de solucionar problemas emergentes e não simplesmente reproduzirem alguns saberes". O estudante precisa perceber que o aprendizado escolar o ajuda a viver melhor, a interagir confiantemente na sociedade, a projetar para si empreendimentos que o insiram no mundo do trabalho e da autorrealização.
Paulo Freire (2016, p. 19) relaciona liberdade e educação à consciência crítica, ao mostrar que "uma educação que procura desenvolver a tomada de consciência e a atitude crítica" liberta em lugar de submeter, de domesticar, de adaptar subalternamente. Assim, o autor chama atenção para a conscientização como princípio fundamental para desencadear uma educação científica. O posicionamento crítico se revela, segundo o autor, a partir de uma tomada de consciência que não pode existir fora da prática e da ação-reflexão.

Nesse sentido, conforme constitutivo do fazer investigativo na Linguística Aplicada, entendemos como essencialmente necessária a (re)aprendizagem de novas práticas, mecanismos e metodologias para informar a atuação pedagógica em sala de aula. Dessa forma, as experiências interventivas compartilhadas representam avanços pertinentes para a abordagem da educação científica no ensino de línguas. Ainda há, indubitavelmente, um longo caminho a ser percorrido para o aprimoramento de questões teóricas e práticas no ensino de línguas, na perspectiva da referida abordagem.

Por fim, ressaltamos que concebemos a investigação científica como uma prática constitutiva do trabalho dos formadores no ensino superior e dos professores no ensino básico. As pesquisas interventivas compartilhadas resultaram da prática investigativa informada por trocas de saberes diversos e, também, do diálogo com experiências realizadas em outros países, a exemplo das apropriações de abordagens pedagógicas produzidas na Linguística Sistêmico-Funcional e, até mesmo, no Ensino de Ciências.

\section{Agradecimentos}

Agradecemos à Coordenação de Aperfeiçoamento de Pessoal de Nível Superior (CAPES) pela bolsa de mestrado profissional concedida às professoras-pesquisadoras coautoras deste artigo. Agradecemos ainda ao Conselho Nacional de Desenvolvimento Científico e Tecnológico (CNPq) pela bolsa de produtividade em pesquisa 
(Proc. 304186/2019-8), concedida ao terceiro autor deste artigo. Os referidos financiamentos contribuíram diretamente para a produção da pesquisa científica aqui compartilhada.

\section{REFERÊNCIAS}

BAGNO, M. Pesquisa na escola: o que é, como se faz. 23. ed. São Paulo: Loyola, 2009. 102p.

BRANDÃO, C. R.; STRECK, D. R. Pesquisa participante e a partilha do saber: uma introdução. In: BRANDÃO, C. R.; STRECK, D. R. (org.). Pesquisa participante: a partilha do saber. Aparecida (SP): Ideias e Letras, 2006, p. $7-20$.

BRASIL. Base Nacional Comum Curricular. Brasília: MEC, 2018. Fonte:

http://basenacionalcomum.mec.gov.br/. Acesso em: 12 set. 2020.

CALLAGHAN, M.; KNAPP, P.; NOBLE, G. Genre in practice. In: COPE, B.; KALANTZIS, M. (ed.). The powers of literacy: a genre approach to teaching writing. London: Falmer Press, 1993. p. 180-189. Disponível em http:// newlearningonline.com/literacies/chapter5/callaghan-knapp-and-noble-on-thegenre-curriculumcycle-or-wheel. Acesso em: 26 nov. 2014.

CELANI, M. A. A. Afinal, o que é linguística aplicada? In: PASCHOAL, M. S. Z.; CELANI, M. A. A. (org.).

Linguística aplicada: da aplicação linguística à linguística transdisciplinar. São Paulo: Educ, 1992. p. 15-23.

CHASSOT, A. Alfabetização científica: questões e desafios para a educação. ljuí: Editora Unjuí, 2014.

FIDELIS, A. C. Proposta de ressignificação de práticas escolares de linguagem pela abordagem do letramento científico no ciclo de alfabetização. Araguaína, 2018. 234f. Dissertação (Mestrado Profissional em Letras ProfLetras) - Programa de Pós-Graduação em Letras. Universidade Federal do Tocantins, 2018.

FREIRE, P. Conscientização. São Paulo: Editora Cortez, 2016.

GARCIA, V.; SILVA, W. R. Planejamento de atividades de práticas de linguagem articuladas em aulas de Língua Portuguesa. In: GOMES, R.; LATTIES, L. (org.). Ensino de línguas na Amazônia: diversidade, tecnologias e multiletramentos. Macapá: Editora da UNIFAP, 2020. p. 25-51.

GUIMARÃES, E. V. Dissertação escolar como prática para investigação pela escrita no contexto escolar. Araguaína, 2019. 184f. Dissertação (Mestrado Profissional em Letras - ProfLetras) - Universidade Federal do Tocantins, Araguaína, 2019.

GUIMARÃES, E. V.; SILVA, W. R. Prática de pesquisa na produção de dissertação escolar. In: FUZA, A. F. F.; PEREIRA, R. A.; RODRIGUES, R. H. (org.). Pesquisas em Linguística Aplicada e práticas de linguagem. Campinas: Pontes Editores, 2020. p. 207-241.

HALLIDAY, M. A. K. Literacy and Linguistics: A Functional Perspective. In: HASAN, R.; WILLIAMS, G. (ed.). Literacy in Society. London: Longman, 1996. p. 339-376

HALLIDAY, M. A. K. Some Grammatical Problems in Scientific English. In: HALLIDAY, M. A. K.; MARTIN, JR (ed.) Writing Science: Literacy and Discursive Power. Pittsburgh: University of Pittsburgh Press, 1993. p. 6985.

HASAN, R. Literacy, everyday talk and society. In: HASAN, R.; WILLIAMS, G. (ed.). Literacy in Society. London: Longman, 1996, p. 377-424.

KLEIMAN, A. B. Agenda de pesquisa e ação em linguística aplicada: problematizações. In: MOITA LOPES, L. P. (org.). Linguística aplicada na modernidade recente: festschrift para Antonieta Celani. São Paulo: Parábola, 2013. p. 39-58.

MARTIN, J. R. Language in Education. Shanghai: Shanghai Jiao University Press, 2012.

MARTINS, I. Letramento científico: um diálogo entre educação em ciências e estudos do discurso. In: MARINHO, M.; CARVALHO, G. T. (org.). Cultura escrita e letramento. Belo Horizonte: Editora UFMG, 2010. p. 363-389

MENDES, J. Letramento científico a partir de textos propagandísticos em aulas de Língua Portuguesa no ensino fundamental. Araguaína, 2018. 251f. Dissertação (mestrado profissional) - Mestrado Profissional em Letras (ProfLetras). Universidade Federal do Tocantins (UFT).

MENDES, J.; SILVA, W. R. Pesquisa escolar sobre contos de fadas como intertextos em publicidades impressas. In: Rosemar Eurico Coenga; Fabiano Tadeu Grazioli. (org.). Leitura e literatura infantil e juvenil: travessias e atravessamentos. São Paulo - SP: Pimenta Cultural, 2020, v. 1, p. 147-177.

MONTEIRO, K. C. S.; SILVA, W. R. Circuito curricular mediado por gênero no ciclo de alfabetização. In: RODRIGUES, R. H.; PEREIRA, R. A. (org.). Práticas de linguagem na esfera escolar. São Carlos: Pedro \& João, 2018. p. 172-205.

PEDROSA, J. C. Por que temos Sotaque? [S.I.]: Língua e Cultura, 2015. Disponível em: https://linguaeculturajuliopedrosa.wordpress.com/2015/0 3/10/por-que-temos-sotaque/. Acesso em: 22 nov. 2020.

PENNYCOOK, A. Critical Applied Linguistics: a critical introduction. New York: Routledge, 2001.

PENNYCOOK, A. A Linguística Aplicada dos anos 90: em defesa de uma abordagem crítica. In: CAVALCANTI, M. C.; SIGNORINI, I. (org.). Linguística Aplicada e transdisciplinaridade. Campinas: Mercado de Letras, 1998, p. 23-49. 
REIS, A. P. Letramento científico como prática inovadora numa escola pública araguainense. Araguaína, 2016. 236f. Dissertação (Mestrado Profissional em Letras ProfLetras) - Universidade Federal do Tocantins, Araguaína, 2016.

REIS, A. P.; SILVA, W. R.; FREITAS, M. O. Gêneros mediadores de letramentos e educação científica do professor de língua portuguesa. Confluência, Rio de Janeiro, 2021. (no prelo)

RIBEIRO, M. H. C. Contribuições do letramento científico para o trabalho pedagógico cooperativo entre as disciplinas de Português e Geografia. Araguaína, 2018. 261f. Dissertação (Mestrado Profissional em Letras ProfLetras) - Programa de Pós-Graduação em Letras. Universidade Federal do Tocantins, 2018.

SANTANA, B. R.; SILVA, W. R.; FREITAS, M. O. O Show da Luna como gênero mediador de educação científica. Ciência e Educação, Bauru, 2021. (no prelo)

SANTOS, B. S. Um discurso sobre as ciências. 5. ed. São Paulo: Editora Cortez, 2008.

SANTOS, W. L. P. Educação científica na perspectiva de letramento como prática social: funções, princípios e desafios. Revista Brasileira de Educação, Rio de Janeiro, v. 12, n. 36, p. 474-550, 2007.

SILVA. W. R. Letramento ou literacia? Ameaças da cientificidade. In: SILVA, W. R. (org.). Contribuições sociais da Linguística Aplicada. Campinas: Pontes, 2021a. p. 111-162.

SILVA, W. R. (org.). Contribuições sociais da Linguística Aplicada. Campinas: Pontes, 2021b.

SILVA, W. R. Educação científica como abordagem pedagógica e investigativa de resistência. Trabalhos em Linguística Aplicada. Campinas, v. 59, n. 3, p. 2020a. (no prelo)

SILVA, W. R. Conveniência da ciência na política brasileira de alfabetização. Revista X. Curitiba: UFPR, v. 15 , n. 4 , p. $60-66,2020 \mathrm{~b}$.

SILVA, W. R. Letramento e fracasso escolar. 2. ed. Manaus: Editora da 2020c.

SILVA, Wagner R. Polêmica da alfabetização no Brasil de Paulo Freire. Trabalhos em Linguística Aplicada. Campinas: Unicamp, v. 58, n. 1, p. 219-240, 2019 a.

SILVA. W. R. Prática científica na escrita de professora. Linguagem em Discurso. Tubarão: Unisul, v. 19, n. 2, p. 273-292, 2019b.

SILVA, W. R. Construção de práticas de pesquisa no Mestrado Profissional em Letras. In: SILVA, W. R.; BEDRAN, P. F.; BARBOSA, S. A. (org.). Formação de professores de língua na pós-graduação. Campinas: Pontes, 2019c, p. 25-57.

SILVA, W. R. Educação científica como estratégia pedagógica para formação de professoras. Veredas: Revista de Estudos Linguísticos, Juiz de Fora, UFJF, v. 2, n. 23, p. 144-161, 2019d.
SILVA, W. R. Gêneros em práticas escolares de linguagens: currículo e formação do professor. Revista Brasileira de Linguística Aplicada, Belo Horizonte, v. 15, n. 4, p. 1023-1055, 2015.

SILVA, W. R.; GONÇALVES, A. V. Pesquisas a serem lembradas na linguística aplicada: participante e pesquisa-ação. In GONÇALVES, A. V.; SILVA, W. R.; GÓIS, M. L. S. (org.). Visibilizar a linguística aplicada: abordagens teóricas e metodológicas. Campinas, SP: Pontes Editores, p. 53-79, 2014.

SILVA, W. R. Empoderamento de participantes de pesquisa em Linguística Aplicada. Raído, Dourados, v. 4, n. 8, p. 119-139, 2010.

SOARES, M. Alfaletrar: toda criança pode aprender a ler e a escrever. São Paulo: Contexto, 2020.

SOARES, M. Alfabetização e letramento. São Paulo: Contexto, 2003.

SOUSA, B. S. Letramento científico a partir de relatórios de pesquisa no Ensino Fundamental II: uma intervenção pedagógica. 2016. 97f. Dissertação (Mestrado Profissional em Letras) - Universidade Federal do Tocantins, Araguaína, 2016.

\section{COMO CITAR ESSE ARTIGO}

SILVA, Wagner Rodrigues; MENDES, Jaquelene; RIBEIRO, Marcia Helena Costa. COMPREENSÕES SOBRE CIÊNCIAS COMPARTILHADAS POR ALUNOS DA ESCOLA BÁSICA ANTES E DEPOIS DE INTERVENÇÕES PEDAGÓGICAS. Signo, Santa Cruz do Sul, v. 46, n. 86, maio 2021. ISSN 1982-2014. Disponível em:

$<$ https://online.unisc.br/seer/index.php/signo/article/view/15 995>. doi:https://doi.org/10.17058/signo.v46i86.15995. 


\section{Anexo}

Círculo Curricular Mediado por Gêneros

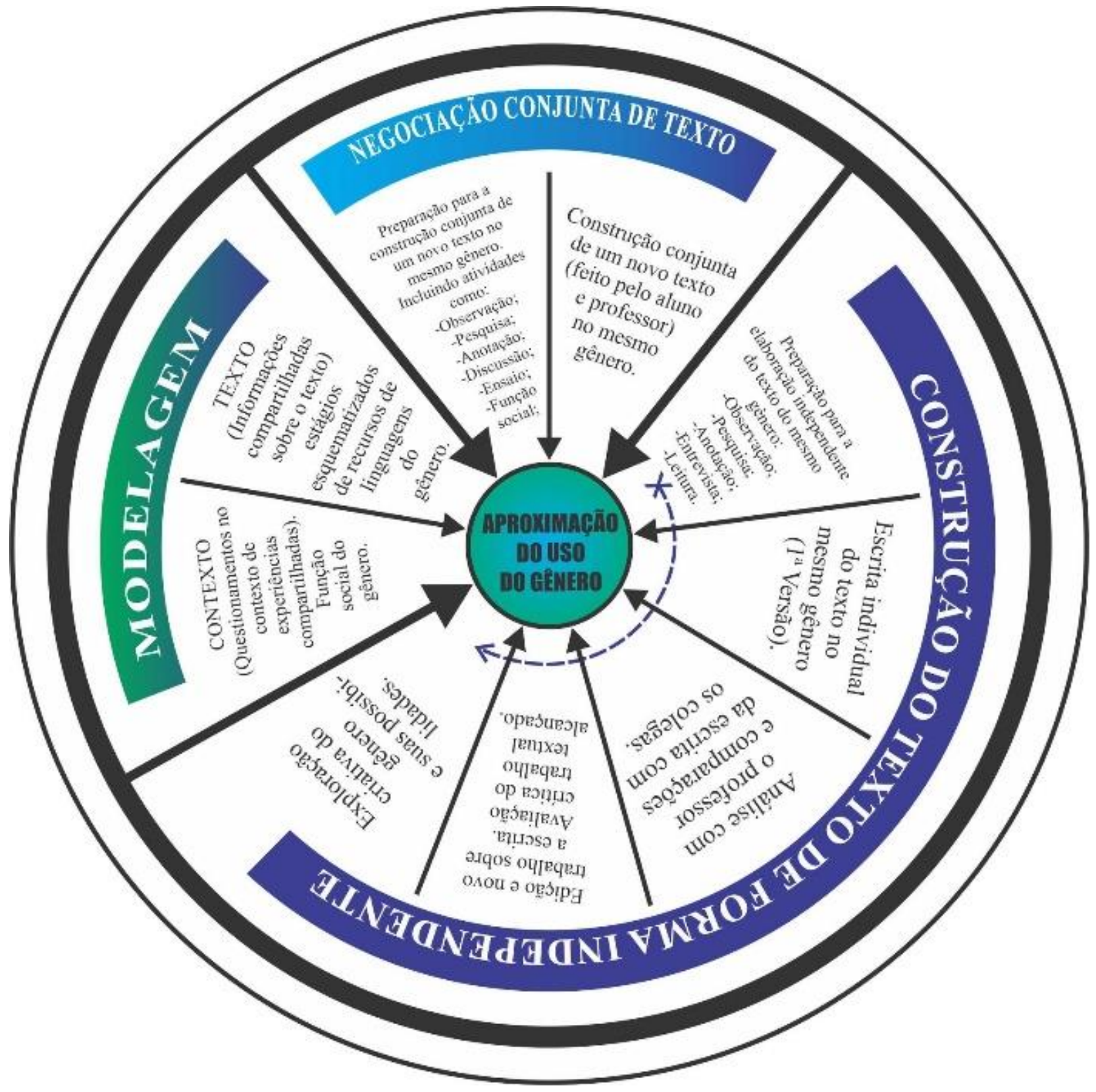

Fonte: (SILVA, 2015, p. 1047). 